\title{
El concepto de libertad en el periodo de la regeneración*
}

\author{
The concept of freedom in the regeneration period
}

\section{0 conceito de liberdade no período da regeneração}

Fecha de entrega: 12 de septiembre de 2016

Fecha de evaluación: 10 de diciembre de 2016

Fecha de aceptación: 25 de enero de 2017

\section{Francisco González Granados**}

En la medida que se haya experimentado el propio tiempo como un tiempo siempre nuevo [...] el reto del futuro se ha hecho cada vez mayor.

(Koselleck)

\section{Resumen}

Koselleck en su escrito Futuro pasado (1993), considera que la historia conceptual permite la comprensión del pensamiento sociopolítico, ya que los conceptos son las herramientas con las que los actores de un momento histórico articularon sus estructuras sociopolíticas, y proyectaron diversas expectativas sobre su futuro. Por otra parte,

* El presente escrito está relacionado con la investigación que el autor realiza en su tesis de doctorado. DOl:http://dx.doi.org/10.15332/s0120-8462.2017.0116.05

* Doctorando en Filosofía de la Universidad Nacional. Magister en Filosofia de la misma universidad, licenciado en Filosofia de la Universidad Santo Tomás. Beneficiario convocatoria 7272015 Colciencias. Correo electrónico: gragonfra@gmail.com 
la implementación de la historia conceptual en el estudio del pensamiento sociopolítico latinoamericano, ofrece a la historia social y a la filosofía política una nueva mirada sobre la consolidación, el cambio o desaparición de las sociedades, sus instituciones y sus conceptos políticos fundamentales. En este escrito, en tres momentos, se presenta una aproximación sobre la libertad y su importancia como concepto fundamental del pensamiento sociopolítico en el periodo de la Regeneración. Primero, se describen los lineamientos generales de la historia conceptual. Segundo, se expone la influencia de la historia conceptual en el estudio del pensamiento sociopolítico latinoamericano. Tercero, se ven las posibilidades del análisis del concepto libertad durante el periodo de la Regeneración.

Palabras clave: historia conceptual, concepto, sociopolítico, libertad, Regeneración.

\section{Abstract}

Koselleck, in his work Future past (1993), considers that conceptual history allows the understanding of sociopolitical thought, since concepts are the tools with which the actors of a historical moment articulated their sociopolitical structures, and projected diverse expectations about their future. On the other hand, the implementation of conceptual history in the study of Latin American sociopolitical thought offers a new perspective on social history and to the political philosophy a new view on the consolidation, change or disappearance of societies, their institutions and their main political concepts. In this paper, in three moments, an approach is presented on freedom and its importance as a fundamental concept of sociopolitical thought in the Regeneration period. First, the general outlines of conceptual history are described. Second, the influence of conceptual history on the study of Latin American sociopolitical thought is presented. Third, the possibilities of the analysis of the concept of freedom during the Regeneration period are shown.

Keywords: conceptual history, concept, sociopolitical, freedom, Regeneration. 


\section{Resumo}

Koselleck no seu texto Futuro pasado (1993) considera que a história conceitual permite a compreensão do pensamento sociopolítico, porque os conceitos são as ferramentas dos atores de um movimento histórico articularam suas estruturas sociopolíticas e projetaram diversas expectativas sobre seu futuro. De outro lado, a implementação da história conceitual no estudo do pensamento sociopolítico latino-americano, oferece para a historia social e para a filosofia política um novo olhar sobre a consolidação, a mudança ou desaparição das sociedades, suas instituições e seus conceitos políticos fundamentais. Em este texto, em três momentos, se apresenta uma aproximação sobre a liberdade e sua importância como conceito fundamental do pensamento sociopolítico no período da Regeneração. Primeiro, descrevem-se as características gerais da historia conceitual. Segundo, expõe-se a influencia da histórica conceitual no estudo do pensamento sociopolítico latino-americano. Terceiro, observam-se as possibilidades da análise do conceito liberdade durante o período da Regeneração.

Palavras-chave: história conceitual, conceito, sociopolítico, liberdade, Regeneração. 


\section{La historia conceptual (begriffsgeschichte)}

La historia conceptual en la aplicación de su teoría ha construido como uno de sus más destacados aportes el Diccionario histórico de conceptos político-sociales básicos (geschichtliche grundbegriffe), que presenta un desarrollo de la teoría planteada por Koselleck junto con la colaboración de Brunner y Conze. Por otro lado, la historia conceptual, según Koselleck (1993):

Se ocupa de textos y palabras [...] cuyos métodos, que proceden del ámbito de la historia de la terminología filosófica, de la filología histórica, de la semasiología y de la onomasiología [...] atienden al uso de los términos relevantes social o políticamente (Koselleck, p. 105).

Con los términos o las palabras se construye la comprensión de un momento cronológico. Los términos usados, las construcciones lingüísticas en las que surgieron o las que modificaron, son una vía para analizar la comprensión que tenían de sí mismos y de su entorno los agentes de una zona territorial y de un momento cronológico específico. ¿Qué nos dicen estos términos no solo sobre las estructuras sociales o políticas sino también sobre sí mismos? Esta fue una de las preguntas que se realizó Koselleck. El autor propone que a partir del estudio de los términos se puede establecer una relación entre cómo es la elaboración de las experiencias sobre el pasado y las expectativas sobre el futuro, en una época concreta, ya que por medio de dichos términos se pueden condensar vivencias o generar expectativas respecto al tiempo pasado, al presente y al futuro.

La comprensión sobre las relaciones entre lo que llamamos pasado, presente y futuro se enmarcan en una categoría que Koselleck denominó el tiempo histórico. Este no se corresponde exactamente con el tiempo cronológico, en el que están inmersos los actores de una época específica, sino que surge de las tensiones generadas por las relaciones entre cómo se concibió el pasado, cómo se concibe el presente y cómo se prevé el futuro:

El tiempo histórico [...] está vinculado a unidades políticas y sociales de acción, a hombres concretos que actúan y sufren, a sus instituciones y organizaciones [...] la determinación de la diferencia entre pasado y futuro, o, [...] entre 
experiencia y expectativa se puede concebir algo así como el tiempo histórico (Koselleck, 1993, p. 14).

La categoría del tiempo histórico permite elaborar un estudio sobre las organizaciones políticas o sociales, sus actores, a través del estudio de las fuentes escritas gracias a que:

La terminología sociopolítica del lenguaje de las fuentes posee una serie de expresiones que se pueden destacar definitoriamente como conceptos [...] cada concepto depende de una palabra, pero cada palabra no es un concepto social y político. Los conceptos sociales y políticos contienen una concreta pretensión de generalidad y son siempre polisémicos. [...] Un concepto tiene que seguir siendo polívoco para poder ser concepto. También él está adherido a una palabra, pero es más que una palabra: una palabra se convierte en concepto si reúne la totalidad de un contexto de experiencia y significado sociopolítico, en el que se usa y para el que se usa una palabra, pasa a formar parte globalmente de esa única palabra [...] los conceptos son, pues, concentrados de muchos contenidos significativos. Los significados de las palabras y lo significado por ellas pueden pensarse por separado. En el concepto concurren significaciones y lo significado, al pasar a formar parte de la polivocidad de una palabra la pluralidad de realidad y de experiencias históricas. Una palabra contiene posibilidades de significado, un concepto unifica en sí la totalidad del significado. Así, un concepto tiene que ser claro, pero tiene que ser polívoco (Koselleck, 1993, p. 117).

El concepto permite analizar la experiencia histórica de una geografía y demografía específica; además ofrece indicadores de cómo fueron las articulaciones y estructuras sociales, razón por la que la historia conceptual está relacionada con la historia social, ya que gracias a los resultados de esta última, la primera toma puntos de referencia cronológicos sobre una sociedad determinada. Koselleck en el capítulo 6 de Futuro pasado (1993) y en los capítulos 1 y 2 de Historia de conceptos (2012), expone las relaciones entre la historia conceptual y la historia social: diferencias teóricas, puntos de encuentro, puntos de divergencia y aportes. La historia conceptual clarifica los conceptos con los que la historia social piensa una época y los conceptos que han adquirido la función de categorías. Por su parte la historia social ofrece información 
sobre la estructura social en la que se usó una terminología sociopolítica; es decir, ofrece información extralingüística que no se obtiene del concepto mismo.

Por otra parte, en la cita anterior, Koselleck enfatiza que el concepto no solo nos ofrece acceso a la experiencia histórica sino que también nos permite captar la "historicidad de sí mismo", es decir, el cambio de sentidos y significados que ha adquirido en un contexto determinado: ¿Cómo fue un concepto en un momento histórico específico?, ¿cómo ha ido cambiando?, ¿cuáles problemas o discusiones se dieron en torno suyo?, ¿cuáles líneas discursivas o tensiones del pensamiento político incorporaron determinado concepto?, ¿cuáles problemas se reactualizaron o desaparecieron con el cambio de sentido de un concepto?, ¿qué posibilidades de acción generó un concepto para una época? Las anteriores preguntas son abordadas por nuestro autor desde la perspectiva de la diacronía y sincronía del concepto. La primera reconstruye los distintos significados que ha recogido el concepto, "sus capas de sentido", y la segunda nos permite analizar cómo fue un concepto en un momento histórico específico, si fue un concepto fundamental o concepto secundario.

La historia del concepto, su diacronía, es como un lazo que tiene muchas sinuosidades y metros de extensión; en cambio, su sincronía, es como si hiciéramos un corte transversal para observar las numerosas fibras que lo componen junto con sus entrelazamientos ${ }^{1}$. La diacronía acude a la onomasiología y la semasiología del concepto. La primera implica rastrear los significados referidos bajo una misma palabra. La segunda, implica establecer si un significado fue denominado con otras palabras similares y su relación. Así, tanto con la diacronía y la sincronía de un concepto se pueden establecer las siguientes relaciones entre un concepto y un estado de cosas significado:

1. El significado de una palabra y el estado de cosas permanecen iguales sincrónica y diacrónicamente. [...] 2. El significado de una palabra permanece igual pero el estado de cosas se modifica. [...] 3. El significado de una palabra cambia, pero la realidad que antes captaba permanece igual. [...] 4. Los estados de cosas y los significados se desarrollan de forma completamente separada de modo que la relación que existía antes ya no se comprende (Koselleck, 2012, p. 32).

1 El anterior ejemplo lo tomé de la explicación ofrecida por el profesor Fernández Sebastián, durante el ciclo de sus conferencias, en la Universidad Nacional, previo al XVII Congreso Colombiano de Historia. 
Sobre estas cuatro relaciones entre el concepto y el estado de cosas, el autor hace hincapié sobre la circunstancia de que tanto el concepto como la realidad que capta no cambian simultáneamente. En ocasiones un cambio del concepto puede determinar un nuevo estado de cosas (concepto generador de experiencias) o un estado de cosas puede generar nuevos conceptos o reincorporar antiguos (concepto de registro de experiencias). La diacronía del concepto aparte de ofrecernos la historia del concepto mismo, también nos facilita indicadores de cómo un grupo social se comprendió a sí mismo y comprendió su tiempo; cuáles visiones tenían sobre su pasado o qué esperaban de su futuro. En cuanto al presente de un grupo social, cabe decir que la sincronía del concepto facilita establecer no solo su significado adquirido, sino también el uso que los agentes de una época hicieron del concepto. Si fueron conceptos democratizados, temporalizados, ideologizados, politizados o emocionalizados. Para una ampliación de estos aspectos de los conceptos, se aconseja el estudio introductorio al geschichtliche grundbegriffe, realizado por el mismo Koselleck y traducido al español por Luis Fernández Torres. En la revista Antrophos n. ${ }^{\circ} 223$ : un texto fundacional de Reinhart Koselleck. Introducción al diccionario histórico de conceptos político-sociales básicos en lengua alemana (pp. 92-105).

Así, el camino señalado por Koselleck permite construir un universo semántico de la terminología sociopolítica de una época, con el fin de interpretar y reconstruir -heurísticamente- sus estructuras y problemas político-sociales, cómo sus actores comprendieron su experiencia histórica y las expectativas de futuro que se plantearon a través de los conceptos.

\section{La historia conceptual en Latinoamérica}

La aplicación de los lineamientos de la historia conceptual en Latinoamérica ha generado una veta de estudios permitiendo una nueva interpretación de nuestra tradición política que no se circunscribe a considerar el pensamiento político y social como mera recepción, adecuación o desviación de las ideas político-sociales o filosóficas provenientes de Europa. Cabe destacar los siguientes trabajos sobre la historia conceptual e historia intelectual: Palti, E. El tiempo de la política (2007). Altamirano, C. Historia de los intelectuales (2008), 2 vols. Altamirano, C. Introducción general. Myers, J. Los intelectuales latinoamericanos desde la colonia hasta el inicio del siglo XX. Schwarz, R. As ideas fora de lugar (1975). Posada, E. El desafío de las ideas. Ensayos de historia intelectual y política en Colombia (2003). Gómez García, J. Intelectuales y vida 
pública en Hispanoamérica siglos XIX y XX (2011). Loaiza, G. Poder letrado. Ensayos sobre historia intelectual de Colombia, siglos XIX y XX (2014). Algunos otros trabajos consultados que abordan el pensamiento político y social desde la perspectiva de la historia de las ideas: Filosofía de la emancipación en Colombia, selección de textos e introducción por Germán Marquínez Argote (1983). La filosofía en Colombia: historia de las ideas, Marquínez et al. (1992).

La historia conceptual permite reconstruir los campos semánticos, los espacios de experiencia y los horizontes de expectativas del pensamiento político y social latinoamericano, de tal manera que se logre una reflexión acerca de los problemas políticos y sociales surgidos en el pasado y la forma en que los conceptos que articularon las estructuras sociales y políticas previas han llegado a nosotros y han posibilitado nuestro presente.

Respecto a los trabajos de historia conceptual en Latinoamérica, sobre el pensamiento político del siglo XIX, es preciso mencionar la propuesta de Palti (2007) que considera este siglo como un "laboratorio político":

El siglo XIX va a ser un momento de refundación e incertidumbre, en que todo estaba por hacerse y nada era cierto y estable. Quebradas las ideas e instituciones tradicionales, se abriría un horizonte vasto e incierto. Cuál era el sentido de esos nuevos valores y prácticas a seguir era algo que solo podría dirimirse en un terreno estrictamente político. Esto que [...] nos resulta insondable no es sino ese momento en que la vida comunal se va a replegar sobre la instancia de su institución, en que la política, en el sentido fuerte del término, emerge tiñendo todos los aspectos de la vida social (p. 13).

Durante el siglo XIX las circunstancias políticas de las antiguas colonias españolas se transformaron, situación que conllevó a una reconfiguración de los problemas, lenguajes y discursos políticos, tal y como lo afirma Fernández Sebastián (2009) al referirse al mundo iberoamericano como una zona en la que conceptos centrales del pensamiento político moderno sufrieron grandes cambios al "vernaculizarse" en las nuevas naciones:

Con la consolidación de las nuevas repúblicas, dentro de cada Estado se desarrollan diferentes líneas discursivas, adaptadas a una política propia y una 
literatura peculiarmente nacional, procesos que lógicamente tienden a incrementar las diferencias en la conceptualización de la política entre los distintos territorios (Fernández y Aljovín, 2009, p. 35).

Conceptos del pensamiento político tales como: soberanía, nación, pueblo, libertad, orden, entre otros, condensarán experiencias históricas, relaciones teóricas y prácticas con múltiples semejanzas y diferencias en la región latinoamericana, tal y como es el caso del concepto de libertad:

Durante el siglo 1770-1870, los sentidos de la libertad fluctuarían a través de cuatro tensiones inherentes a la historia del concepto: la unidad y el orden frente a la división y el conflicto; la libertad de la comunidad y la libertad del individuo; la libertad del ciudadano y la autoridad del poder político y religioso; finalmente, la tensión entre individuos iguales ante la ley, y desiguales en la práctica de la libertad (Fernández y Aljovín, 2014, p. 48) (letra en cursiva, énfasis del autor).

Las siguientes dos obras ofrecen un panorama sobre la terminología política y social de distintas regiones latinoamericanas, ya que cada tomo está constituido por volúmenes dedicados a un concepto desde la perspectiva de cada país latinoamericano: Iberconceptos I o diccionario político y social del mundo iberoamericano. La era de las revoluciones, 1750-1850, vol. I. de Javier Fernández Sebastián. E Iberconceptos II o diccionario político y social del mundo iberoamericano. Conceptos políticos fundamentales, 1770-1870 del Centro de Estudios Políticos y Constitucionales, Universidad del País Vasco. En el caso del concepto de libertad, en primer lugar, se presenta una síntesis general sobre los sentidos del concepto y sus cambios. Posteriormente, el volumen expone un estudio de ese concepto en el contexto de cada país. El deseo por abordar el estudio del concepto de la libertad en Colombia radica en que, aparte de generar varias líneas discursivas, tuvo un uso político preponderante, en la consolidación de los partidos políticos y las políticas administrativas sobre la regulación de los derechos y deberes de los ciudadanos. La libertad es un término que articula la reflexión de lo político al constituirse, después del siglo XVIII, como un criterio que permite establecer el avance en la consolidación y construcción de las repúblicas y las democracias.

En cuanto al caso de Colombia, las tensiones generadas en torno al concepto de libertad surgieron una vez iniciado el proceso de la independencia: 
Otro tipo de tensiones que se manifestaron con fuerza en el momento independentista fueron generadas por la conjunción conflictiva entre la rápida apropiación de la Libertad como "derecho natural", que otorgaba gran autonomía al individuo, y una asentada tradición de organización social jerárquica. Este conflicto se manifestó en múltiples ámbitos, pero fue especialmente visible en las disputas en torno a la organización política, que hipertrofiaron acendradas rivalidades heredadas del periodo monárquico entre toda clase de poblaciones (Fernández y Aljovín, 2014, p. 127).

Las disputas por definir la libertad conllevaron a que este concepto se ideologizara y politizara, convirtiéndose en un arma teórica de las diferentes posturas políticas sobre la garantía constitucional de la libertad y el mantenimiento de un orden político. Un ejemplo de lo anterior lo encontramos en un análisis histórico de las ideas fundamentales del partido liberal y conservador, hecho por Manuel María Madiedo (1858):

El liberalismo no puede consistir sino en la inviolabilidad práctica de los derechos constitutivos del hombre, como axioma fundamental de todo el orden público de una sociedad. [...] Liberales y conservadores han abogado por la libertad de imprenta, por la libertad religiosa, por la abolición de la esclavitud, por la abolición del cadalso político, por la instrucción gratuita, por la libertad industrial, etc., etc. [...] Lo que se ha llamado partido liberal en este país, no es más que una variación de la escuela conservadora. [...] Una escuela liberal haría esto: en religión, libertad perfecta. En industria, libertad y fomento. En libertad política, toda la del hombre. En libertad de imprenta, la garantía moral del honor. [...] Pero si al lado de la libertad de la idea religiosa escrita en la ley, están la intolerancia y el fanatismo prácticos ¿qué es lo que realmente hay? ¡La burla! Si al lado de la libertad industrial, escrita en la ley, están los monopolios y las contribuciones vejatorias [...] Si al lado de la libertad política escrita en la ley, está la persecución contra el sufragio, las exclusiones políticas por causa de la opinión. [...] Si al lado de la libertad de imprenta, escrita en la ley, está la completa impunidad de la calumnia. [...] ¿Qué es lo que hay realmente? ¡La burla! (pp. 42-43).

La anterior reflexión nos permite acercarnos a un momento histórico que devela una inestabilidad en la consolidación de un sentido unívoco de la libertad. Dicha 
inestabilidad es un síntoma de que sobre el concepto de libertad se están articulando diversas expectativas de lo que debe ser un ordenamiento político que garantice los derechos individuales y el orden social. Las discusiones surgidas sobre la libertad no se dan por separado, sino que están inmersas en debates y proyectos políticos sobre la organización política del país. Lo anterior nos ofrece una ventana para analizar cuál fue la experiencia histórica condensada en el concepto de libertad y su devenir histórico. Al respecto cabe afirmar que:

En una experiencia común a los territorios de las revoluciones atlánticas, el problema de delimitar la libertad constituyó al mismo tiempo una enorme fuente de creación intelectual y una difícil experiencia de pérdida de inocencia política. Más de seis décadas después de los primeros ensayos en autogobierno, la perplejidad provocada por esta palabra llevó a Sergio Arboleda, uno de los primeros estudiosos del vocabulario político en Colombia, a proponer a fines del siglo XIX: "Todos tienen idea exacta y uniforme de lo que es justicia, y cada cual se la forja diversa de lo que es libertad, matemos todo sofisma diciendo justicia donde hasta ahora se ha dicho libertad. Hoy la voz es nueva, preconizadla como tal y tendremos libertad" (Fernández y Aljovín, 2014, p. 135).

La creación intelectual en torno a las discusiones sobre la libertad se dio en diferentes espacios tales como los periódicos, libros, debates y leyes, manteniendo cierta regularidad en la vida política nacional a partir de la independencia y hasta finales del siglo XIX:

La gran divisoria del momento remitió al problema de la libertad en cuanto singular colectivo, tema reactualizado por la consolidación -a pesar de notorias resistencias sociales- de un pequeño e influyente grupo de intelectuales sensualistas. José María Samper ofreció una síntesis del enfoque de estos actores al afirmar: "Para que una sociedad progrese y sea feliz, no es bastante darle instituciones políticas liberales. Es necesario empezar por hacer libre al individuo". [...] Estas estrategias favorecieron inicialmente a los liberales, posibilitando, en 1853, la promulgación de una nueva Constitución Política de Nueva Granada, en la que se formularon nociones de la libertad influyentes en el decurso posterior del concepto (Fernández y Aljovín, 2014, p. 133). 
Una situación privilegiada para acercarse a las discusiones sobre la libertad es la promulgación de las constituciones, ya que en torno a cada una de ellas se agrupan las comprensiones y normalizaciones de los conceptos políticos y los debates subyacentes. Las nociones de libertad que se presentan en la Constitución de 1853 giran en torno a la concepción de la libertad como un derecho ilimitado del individuo tanto a nivel moral, comercial y de opinión pública. La libertad es el derecho primordial que limita la acción estatal:

Art. 5: la República garantiza a todos los Granadinos: 1. La libertad individual, que no reconoce otros límites que la libertad de otro individuo, según las leyes; [...] 4. La libertad de industria i de trabajo, con las restricciones que establezcan las leyes; 5. La profesión libre, pública o privada de la relijion que a bien tengan, con tal que no perturben la paz pública, no ofendan la sana moral, ni impidan a los otros el ejercicio de su culto; 7. La espresión libre del pensamiento; entendiéndose que por la imprenta es sin limitación alguna; i por las palabras y los hechos, con las únicas que hayan establecido las leyes; 8 . El derecho de reunirse pública o privadamente, sin armas, para hacer peticiones a las funcionarios o autoridades públicas [...] i emitir libremente i sin responsabilidad ninguna su opinión sobre ellos (Constitución Política de la Nueva Granada, 1853).

El acercamiento a la comprensión de libertad y su decurso posterior se puede rastrear a través de las diferentes líneas discursivas acerca de cómo usarla en la vida pública, la acción política, el comercio, la imprenta o prensa, la confesión religiosa, la instrucción pública, etc. Otro ejemplo que nos ilustra el decurso del concepto de libertad asociado con la promulgación de una nueva Constitución es el siguiente: "La Constitución de 1853, no solo era la más radicalmente liberal, pues consagraba los más adelantados principios que la filosofía política puede proclamar, armonizando el gobierno de los pueblos por sí mismos, con la plenitud del derecho individual" (Samper, 1873, p. 105). El constante cambio en la comprensión del concepto de libertad y su aplicación en la vida pública mantuvo "la creación intelectual" y las líneas discursivas, en torno a cómo cada partido político o grupos sociales asumían su postura frente a esta:

El radicalismo triunfó no solo en 1853, sino también en el mayor número de legislaturas [...] los artesanos y la juventud radical, antagonismo que cesó completamente [...] su causa era la misma: la libertad democrática, la Regeneración del país en todo sentido (Samper, 1873, p. 100). 
Las discusiones acerca de si la comprensión de la libertad era pertinente para el momento social del país y las consecuencias de cómo fue estipulada en la Constitución se mantienen en la promulgación de la Carta de Rionegro. En esta, la concepción de la libertad sigue asociada con la garantía de los derechos individuales, base esencial de la unión:

3. La libertad individual; que no tiene límites que la libertad de otro individuo [...] 6. La libertad absoluta de imprenta i de circulación de los impresos así nacionales como extranjeros. 7. La libertad de espresar sus pensamientos de palabra o por escrito sin limitación alguna. 8. La libertad de viajar en el territorio de los Estados Unidos [...] 9. La libertad de ejercer toda industria i de trabajar sin usurpar la industria de otro. [...] La libertad de dar o recibir la instrucción que a bien tengan, en los establecimientos que no sean costeados con fondos públicos [...] 14. La libertad de asociarse sin armas. 15. La libertad de tener armas i municiones, $\mathrm{i}$ de hacer el comercio de ellas en tiempo de paz. 16. La profesión libre, pública o privada, de cualquiera religión (Constitución Política de los Estados Unidos de Colombia, 1977, art. 15).

La concepción de libertad de la Constitución reactualiza las discusiones en torno a si es conveniente una libertad ilimitada y cómo el Estado debe regularla, sin atentar contra los derechos individuales. Una línea discursiva sobre los límites de la libertad que ocupó gran parte de la opinión pública fue la referente a la libertad de prensa, ya que a partir de este derecho se realizaron cuestionamientos, críticas y defensas de las otras libertades estipuladas. Tal discusión fue llevada a cabo, principalmente, por los partidos políticos a través de sus periódicos; además, gracias a dicha discusión se delinearon las posturas ideológicas de los partidos durante las décadas posteriores a la Constitución de 1863:

El partido liberal [...] su mayor fuerza no está en su grandeza numérica, sino en la claridad y precisión de su programa. Este programa se condensa en tres ideas cardinales: mantener la federación a todo trance; sostener también a todo trance las libertades y garantías consagradas por el artículo 15 de la Constitución; y promover sin tregua el desenvolvimiento intelectual y material de los pueblos. [...] Si el partido liberal está dividido [...] no está menos el conservador, a juzgar por su prensa. [...] Los tradicionistas (único elemento verdaderamente godo que tiene el partido conservador). [...] He aquí sus ideas: el liberalismo 
es abiertamente contrario al catolicismo. [...] Toda libertad humana que sea condenada en principio por el pontificado, es antirreligiosa y por tanto criminal y perversa. [...] No hay en las sociedades humanas verdaderas cuestiones sociales ni políticas: todo es cuestión de moral y religión (Samper, 1873, p. 135).

Las posturas ideológicas de los partidos en torno a la libertad y las clases de libertades, están inmersas en diferentes contextos discursivos o concepciones políticas: una de carácter religioso, otra de carácter civil y otra que incluía principios tanto religiosos como civiles. La comprensión de la libertad asociada con la esfera religiosa se puede rastrear en editoriales y artículos de periódicos, tales como: El Tradicionista, La Unión Católica; La Regeneración, El Porvenir, La Nación, El Conservador, La Prensa, El Catolicismo.

En cuanto a los actores políticos asociados con dichos periódicos, se destacaron las figuras de Miguel Antonio Caro, Sergio Arboleda, Carlos Martínez Silva, entre otros. Acerca de Miguel Antonio Caro, cabe mencionar que su prolífica actividad como escritor ofrece un material amplio en donde se evidencia que el criterio teológico es el único punto de referencia legítimo desde el que se debe comprender y delinear qué es la libertad y su uso en la vida política y civi. La importancia de Caro radica en que sus escritos remiten a otros actores y escritos políticos sobre el tema, circunstancia que facilita la identificación de líneas discursivas sobre la comprensión e interpretación de la libertad y la experiencia histórica condensada por este concepto. Al respecto, conviene mencionar: La respuesta a la filosofía moral de Ezequiel Rojas (1868), el Estudio sobre el utilitarismo (1869), La unidad católica y la pluralidad de cultos (1869) y otras editoriales dirigidas en contra del Diario de Cundinamarca: noviembre y diciembre de 1871. La razón del escándalo (1872).

En cuanto a la concepción de la libertad desde un criterio civil es conveniente destacar los trabajos editoriales y artículos de periódicos tales como: El Derrumbe, Diario de Cundinamarca, El Eco Liberal, La Escuela Liberal. Entre los actores políticos vinculados a estos periódicos están: José María Samper, Salvador Camacho Roldán, Nicolás Esguerra, Rafael Núñez. Sin embargo, personajes como José María Samper y Rafael Núñez evidencian una tendencia conciliadora entre una comprensión religiosa y civil de la libertad: 
La libertad es un hecho o un derecho. [...] El límite de tal derecho y de tal hecho, está en el bien que la misma libertad pueda producir [...] la libertad del alma, que produce la religión como creencia o convicción (Samper, 1873, p. 169).

Ejemplos sobre lo anterior son: Libertad y catolicismo (1873) de José María Samper. La política natural (1878), Renacimiento y libertad religiosa (1886), El renacimiento $y$ los derechos individuales (1886), La revolución moral (1887) de Rafael Núñez.

"El hombre se agita y Dios lo conduce, ha dicho un eminente pensador. En política, sobre todo, esta verdad profunda tiene aplicación" (Núñez, 1878, p. 49). Así, en términos generales, se puede considerar que la comprensión de la libertad giró en torno a la confrontación de dos visiones, una religiosa y otra secular, sobre el deber ser de la política.

Un rasgo común que se encuentra sobre la comprensión de la libertad, radica en la experiencia histórica que condensó, ya que en las discusiones sobre esta, posteriores a la Constitución de 1863, hay un sentimiento generalizado de que debido a su inadecuada comprensión y errónea aplicación en la vida política, la libertad es una de las causas por las que el país estuvo en una situación caótica, especialmente la libertad de prensa y la libertad religiosa: "Al sostener [la escuela liberal] la libertad absoluta de la palabra hay que aceptar igualmente la libertad absoluta de acción [...] la libertad liberal engendra el despotismo" (Caro, 1872, p. 353), y como argumenta Samper (1873):

El partido liberal no debe, no puede ser enemigo del cristianismo católico [...] la libertad nada tiene que destruir, al contrario: ella es conservadora. [...] La libertad es una luz que alumbra el hogar de los pueblos. [... La libertad y la religión no son antagonistas (p. 199).

\section{Libertad durante la Regeneración}

La reacción que se generó en torno al concepto de libertad, después de la Constitución del 63, fue de expectativa sobre cuál sería el sentido de libertad pertinente a las necesidades sociales y políticas del país. Lo anterior se evidencia en el movimiento regeneracionista y su interpretación de que muchos de los males políticos y sociales 
del país están vinculados a errores sobre la vida política, estipulados en la Constitución de Rionegro, entre los cuales está la comprensión del derecho de la libertad:

¿Qué cosa mejor puede desear el país sino que sus gobiernos tomen sin timidez i sin vacilación la via que conduce a la exaltación nacional? Mantener las libertades públicas con lealtad imperturbable. [...] Hagamos un esfuerzo enérjico i patriótico en favor de la paz [...] i de allí surjirán, por fuerza, las ideas de orden que afiancen la libertad [...] (Trujillo, 1878, p. 307).

En el mismo sentido se expresó Núñez (1878) en el discurso de posesión de Trujillo:

La historia nos enseña que todas las naciones han tenido periodos de crisis, que han determinado el principio de su decadencia, o han sido el punto de partida de un más acentuado progreso. [...] El país se promete de vos, señor, una política diferente; porque hemos llegado a un punto que estamos confrontando este preciso dilema: regeneración administrativa fundamental o catástrofe (p. 307).

La pregunta sobre qué regenerar en el país para superar el momento político de crisis, llevó a Núñez (¿1878?) a reflexionar acerca de qué sentido se le debía dar al término regeneración y la reforma política que implicaba:

Lo que comúnmente se llama Regeneración en el presente periodo de nuestra historia es, más o menos, lo mismo que se llamó Reforma de 1849 a 1853, y Autonomía de los Estados durante la guerra civil de 1860 a 1863. Son esas palabras populares destinadas a caracterizar las épocas de transición de la vida política; o especies de consignas por así decirlo, que hablan acaso más a la imaginación que a la inteligencia. [...] ¿Cuál es esa política? Ella se resume en pocas palabras. Es la política del orden y la libertad fundada en la justicia. Es la política de la justicia fundada en la práctica religiosa y leal de las instituciones. Es, en otros términos, la política de la fuerza moral, reemplazando la política de la fuerza material (Tomo I, p. 65).

Esta interpretación de Núñez nos permite identificar un momento histórico en el que el pensamiento político colombiano se enfrentó a una reflexión y reinterpretación de los conceptos políticos, sobre los cuales se había construido la nación. Entre los 
conceptos señalados se reitera el concepto de libertad como uno de los pilares de la vida republicana. Aparte de las líneas discursivas referidas a la libertad de prensa y religiosa, se reactualiza, con el movimiento regeneracionista, la discusión sobre la libertad de sufragio:

La Regeneración sí implica la alternabilidad [...] por la libertad del sufragio, efectiva. [...] Luego que la libertad de sufragio sea un hecho práctico, [...] se obtendrá este grande y primer resultado: saber lo que el país desea en materia de principios políticos (Núñez, 1878, p. 36).

Uno de los objetivos de la Regeneración fue ampliar la participación política con el fin de alcanzar un consenso general sobre el porvenir de la nación; además, Núñez nos ofrece un ejemplo de reflexión histórica sobre la necesidad de cambiar los principios políticos. Las discusiones sobre los conceptos políticos fundamentales desembocarán en la propuesta de crear una nueva constitución:

Art. 1. Excítase á los gobiernos de los Estados para que envíen delegatarios a un Consejo Nacional que habrá de reunirse el 11 de noviembre próximo en la capital de la Unión, para deliberar sobre los términos en que debe procederse á la reforma de la Constitución (Presidencia de la República de los Estados Unidos de Colombia, 1885).

Entre los temas centrales que debían ser reformados figura el de la libertad, tal y como lo expresó Núñez (1885) en su mensaje al Consejo Nacional de Delegatarios:

Hicimos, en suma, de la libertad humana un ideal estúpido, semejante a los ídolos sangrientos de las tribus bárbaras, cenagoso manantial de pasiones ciegas que, comenzando por perturbar el criterio, sumergían a cada ciudadano en la más lastimosa de las servidumbres, cual es la depresión moral (p. 46).

Posteriormente, en la Constitución de 1886, llama la atención la ausencia de un artículo que enuncié explícitamente cuáles son las libertades, a diferencia de las constituciones anteriores, sino que en el título III se estipulan los derechos que tiene el ciudadano: prohibición de la esclavitud, derecho a un debido proceso, en caso de ser detenido (con excepciones), libertad de cultos y reconocimiento del catolicismo 
como religión oficial, libertad de prensa, en tiempos de paz, entre otros. Lo anterior puede considerarse como un intento de neutralizar el concepto de libertad con el fin de evitar las discusiones acerca de cómo ejercer la libertad individual. Al respecto, Núñez (1886) señala: "la nueva Constitución comienza invocando el nombre de Dios, tontamente desterrado de nuestros documentos públicos. [...] Los rasgos sobresalientes de la Reforma pueden enumerarse así: libertad religiosa; unidad nacional; derechos para todos; estabilidad y autoridad" (p. 173). "Esa Constitución [...] realiza la necesaria conciliación de la libertad individual con el orden social" (Núñez, 1886, p. 172).

Acorde a lo anterior, podemos considerar que la libertad como concepto registró las experiencias sobre cómo se ejerció como un derecho constitucional. Podría decirse que el concepto de libertad, entre la Constitución de 1863 y la Constitución de 1886, evolucionó de una forma acelerada respecto al estado de cosas que significaba. Posterior a la Constitución de 1886, cabría la posibilidad de considerar si la libertad adquirió una connotación como concepto generador de expectativas, con el que se intentó cambiar un estado de cosas.

Finalmente, tanto las discusiones surgidas sobre el concepto de libertad, posteriores a la Constitución de Rionegro, como las que se dieron sobre cómo consagrar la libertad en la Constitución del 86 y las que se generaron después de esta, ofrecen un campo de exploración sobre los sentidos de la libertad durante el periodo de la Regeneración, que nos permiten un redescubrimiento del pensamiento sociopolítico de esta época desde la perspectiva de la historia conceptual. 


\section{Referencias}

Caro, M. (1871). Editorial. El Tradicionista, 1 (p. 1).

Caro, M. (1871). Principios y hechos. La Unión Católica, 7, (p. 25).

Caro, M. (1871). Escuela liberal. La Unión Católica, 8, (p. 29).

Caro, M. (1872). El carro de la libertad. El Tradicionista, (pp. 352-353).

Caro, M. (1872). El liberalismo se va. El Tradicionista, 51, (pp. 311-312).

Caro, M. (1872). Libertad liberal. El Tradicionista, 57, (pp. 337-338).

Caro, M. (1882). Libertad Radical. El Conservador, 4, (78), 310-311.

Caro, M. (1888). Libertad de imprenta. La Nación, (pp. 308-333).

Colombia. (1871). Constitución política de los Estados Unidos de Colombia. Bogotá: Imprenta Esterotípia de Medardo Rívas.

Duso, G. (1998). Historia conceptual como filosofía política. Res pública, (pp. 35-71).

Girardin, E. D. (1872). El derecho de castigar. Diario de Cundinamarca, 76, (pp. 836-837).

Fernández, J. S., y Aljovín, C. (2014). Libertad. Diccionario político y social del mundo iberoamericano. Conceptos políticos fundamentales, 1770-1870, 10. Madrid: Centro de Estudios Políticos y Constitucionales - Universidad del País Vasco.

Fernández, J. S., y Aljovín, C. (2014). Libertad. Diccionario político y social del mundo iberoamericano. Conceptos políticos fundamentales, 1770-1870, 10. Madrid: Centro de Estudios Políticos y Constitucionales - Universidad del País Vasco.

Fernández, J. S. (2009, 2014). Libertad. Diccionario político y social del mundo iberoamericano, 11. Madrid: Centro de Estudios Políticos y Constitucionales.

Koselleck, R. (1993). Futuro pasado. España: Paidós.

Koselleck, R. (1997). Historia y hermenéutica. Barcelona: Paidós.

Koselleck, R. (2001). Los estratos del tiempo. Barcelona: Paidós. 
Koselleck, R. (2004). Historia: historia. Madrid: Trotta.

Koselleck, R. (2012). Historia de conceptos. Madrid: Trotta.

La Convención Nacional. (1863). Constitución Política de los Estados Unidos de Colombia. Recuperado de http://www.banrepcultural.org/sites/default/files/ brblaa1243262.pdf

Liévano, I. E. (1945). La Reforma Política en Colombia. Bogotá: Biblioteca Popular de Cultura Colombiana.

Madiedo, M. (1858). Ideas fundamentales de los partidos políticos de la Nueva Granada. Orígenes de los partidos políticos en Colombia, (pp. 27-57). Bogotá: Biblioteca Básica Colombiana.

Núñez, R. (1885). Mensaje al Consejo Nacional de Delegatarios. En J. Uribe, E. Lemaitre, C. Valderrama, y A. Restrepo. Núñez y Caro 1886 (1986), (pp. 39-48). Bogotá: Banco de la República.

Núñez, R. (1878). Discurso posesión del presidente general Trujillo. Diario de Cundinamarca, (pp. 307-308).

Núñez, R. (1878). La política natural. En I. Liévano. La Reforma Política en Colombia. Colección de artículos y discursos publicados en el Impulso y el Porvenir de Cartagena, La Nación de Bogotá (1945), (pp. 49-55). Bogotá: Biblioteca Popular de Cultura Colombiana.

Núñez, R. (1878). Vamos al fondo. En I. Liévano. La Reforma Política en Colombia. Colección de artículos y discursos publicados en el Impulso y el Porvenir de Cartagena, en la Nación de Bogotá, (pp. 35-38). Bogotá: Biblioteca Popular de Cultura Colombiana.

Núñez, R. (1886). El renacimiento y la libertad religiosa. En I. Liévano Aguirre. La Reforma Política en Colombia. Colección de artículos y discursos publicados en el Impulso y el Porvenir de Cartagena, en La Nación de Bogotá, (pp. 173-179). Bogotá: Biblioteca Popular de Cultura Colombiana.

Núñez, R. (1886). El renacimiento. En I. Liévano Aguirre. La Reforma Política en Colombia. Colección de artículos y discursos publicados en el Impulso y el Porvenir 
de Cartagena, en La Nación de Bogotá (1945), (pp. 165-172). Bogotá: Biblioteca popular de cultura colombiana.

Palti, E. (2001). Ideas, conceptos, metáforas. La tradición alemana de historia intelectual y el complejo entramado del lengüaje. Res publica, (pp. 227-248).

Palti, E. (2007). El tiempo de la política: el siglo XIX reconsiderado. Buenos Aires: Editorial Siglo XXI.

Poder Ejecutivo Nacional. (1886). Constitución Política de Colombia. Diario oficial. Bogotá: Imprenta de vapor de Zalamea.

Presidencia de la República de los Estados Unidos de Colombia. (1885). Por el cual se convoca un Consejo Nacional de Delegatarios. [Decreto n.o 594]. DO: 1.

Samper, J. M. (1873). Libertad y catolicismo. En J. Melo (Ed.). Orígenes de los partidos politicos en Colombia, (pp. 160-191). Bogotá: Andes.

Samper, J. M. (1873). Los partidos en Colombia. En J. Melo (Ed.). Orígenes de los partidos políticos en Colombia, (pp. 59-172). Bogotá: Imprenta de Echeverría Hermanos.

Samper, J. M. (1873). Curso elemental de ciencia de la legislación. Bogotá: Imprenta de Gaitán.

Senado y Representantes de la Nueva Granada. (1853). Constitución Política de la Nueva Granada. Recuperado de: http://www.banrepcultural.org/sites/default/ files/brblaa169689.pdf

Trujillo. (1878). Discurso del Jeneral Trujillo. Diario de Cundinamarca, p. 307.

Valderrama, C. (1990). Miguel Antonio Caro. Escritos políticos. Segunda serie. Bogotá: Instituto Caro y Cuervo. 